\title{
Petrografia e química mineral do Stock Granítico Serra do Barriga (Sobral, CE, nordeste do Brasil)
}

\author{
Irani Clezar MATTOS ${ }^{1}$, José de Araújo NOGUEIRA NETO ${ }^{1} \&$ Antonio Carlos ARTUR ${ }^{2}$
}

1 Departamento de Geologia, Universidade Federal do Ceará. Campus Universitário do Pici, Bloco 912, CEP 60455-760, Fortaleza, CE, Brasil (irani.mattos@ufc.br, nogueira@ufc.br).

2 Departamento de Petrologia e Metalogenia, Instituto de Geociências e Ciências Exatas, Universidade Estadual Paulista. Campus de Rio Claro. Av. 24-A, 1515, Bela Vista, CEP 13506-900, Rio Claro, SP, Brasil (acartur@rc.unesp.br).

Recebido em 05/2016. Aceito para publicação em 11/2017.

Versão online publicada em 16/3/2018 (www.pesquisasemgeociencias.ufrgs.br)

Resumo - O Stock Granítico Serra do Barriga (SGSB), localizado a NNW do Ceará, nordeste do Brasil, apresenta variação faciológica que permite exploração comercial em quatro tipos de rochas ornamentais: Rosa Iracema (RI), Rosa Olinda (RO), Branco Savana (BS) e Branco Cristal Quartzo (BCQ). 0 objetivo deste trabalho é determinar a paragênese, a composição química e a classificação dos principais minerais, além das relações genéticas entre as fácies graníticas. Foram realizadas análises petrográficas, utilizando-se lâminas delgadas e análises de química mineral através de microssonda eletrônica. As análises petrográfica e de química mineral mostram que o SGSB varia de sienogranitos e monzogranitos inequigranulares a porfiríticos e não ocorrem diferenças significativas nas composições dos minerais entre as fácies, exceto ligeiras variações no teor de Or nos KF. 0 feldspato potássico é ortoclásio, o plagioclásio mostra transição de albita para oligoclásio. A biotita corresponde a annita com tendência a siderofilita, enquanto o anfibólio corresponde a ferro-edenita. As transformações minerais pós-magmáticas ou hidrotermais como exsolução, potassificação, albitização, cloritização, sericitização e neoformação de fluorita são comuns no SGSB e contribuem na "descoloração" das fácies rosas para as brancas. No plagioclásio dos granitos brancos ocorre frequente sericitização sobreposta à microclinização, com neoformação de fluorita. Todos os dados convergem para a ideia de que as fácies foram formadas por um mesmo evento magmático, sendo que os sienogranitos (RI, RO e BCQ) correspondem à faciologias originadas por um mesmo magma, seguido por um novo pulso magmático mais máfico, representado pelo monzogranito porfirítico (RO).

Palavras-chave: variação faciológica, química mineral, classificação mineral, granito.

Abstract - Petrography AND Mineral Chemistry of SERra do BARriga Granitic Stock (Sobral, CE, NorThEAST of BrASIL). The Serra do Barriga Granitic Stock (SGSB), located at NNW of the Ceará, northeast of Brazil, presents faciological variation that permits commercial exploitation in four types of ornamental rocks: Rosa Iracema (RI), Rosa Olinda (RO), Branco Savana (BS) and White Crystal Quartz (BCQ). The aim of this paper is to investigate mineral association, chemical composition and classification of the main minerals phases, as well as genetic relationships among the granitic facies. Petrographic analyzes were made using thin section and analyzes of mineral chemistry through electron microprobe. Petrographic and mineral chemistry analyzes show that SBGS lithotypes varies from inequigranular to porphyritic syenogranites and monzogranites and different facies do not show significant differences in mineral composition, except for small variations of Or amount in K-feldspar. Potassium feldspar is orthoclase and plagioclase ranges from albite to oligoclase (Ab-Or- to Ab-Or). Biotite corresponds to annita to siderophyllite, while amphibole corresponds to iron-edenite. Post-magmatic or hydrothermal mineral transformations such as exsolution, potassification, albitization, chloritization, sericitization and neoformation of fluorite are common and control discoloration from the pink to the white facies (BS and BCQ). In the plagioclase of the white granites frequent sericitization occurs superimposed to the microclinization, with neoformation of fluorite. The whole data converge to the knowledge that all the facies were formed at the same magmatic event, being the syenogranites (RI, RO and BCQ) originated by an unique magma, followed by a new, more mafic magmatic pulse, represented by porphyritic monzogranite (RO).

Keywords: facies variation, mineral chemistry, mineral classification, granite. 


\section{Introdução}

Na Província Borborema, nordeste do Brasil, é predominante a presença de extensas zonas de cisalhamento, ao longo das quais ocorreram posicionamentos de corpos com variadas dimensões de rochas predominantemente graníticas e granodioríticas de idade neoproterozoica. 0 posicionamento e a exposição destes corpos geraram grandes potenciais para rochas ornamentais.

O objeto deste trabalho é o Stock Granítico Serra do Barriga (SGSB), cuja variação faciológica permite sua exploração comercial como rocha ornamental. A resistência das rochas ornamentais está condicionada às suas características mineralógicas, estruturais, texturais, físico-mecânicas e geoquímicas. O SGSB apresenta mudanças de texturas, cores e tonalidades que resultam da incorporação de novos pulsos magmáticos, bem como da assimilação de xenólitos da rocha encaixante e de alterações tardi a pós-magmáticas. Em função destas variações é possível distinguir vários tipos mineralógicos. A caracterização petrográfica e a química mineral adquirem relevância como ferramenta de apoio na determinação do uso dessas rochas como rochas ornamentais.

Os dados sobre petrografia e química mineral do SGSB são considerados bastante incipientes, visto que não existem publicações que tratam estas questões. Neste contexto, o presente trabalho visa contribuir para esse conhecimento, para isso foi realizado um estudo petrográfico de detalhe e de química das principais fases minerais. Isto permitiu um melhor entendimento sobre a composição dos principais minerais, suas relações genéticas com o granito (sin ou epigenéticas) e a classificação destes minerais.

\section{2 Área, materiais e métodos}

\subsection{Contexto geológico e localização}

Na Província Borborema, a Orogênense Brasiliana mostra uma intensa granitogênese, sendo que no Domínio Ceará Central (DCC, fig. 1) grande parte dos granitos brasilianos são posteriores tanto à tectônica tangencial como à transcorrente, enquadrados como granitos tardi ou pós- tectônicos, com cerca de 585 Ma (Almeida, 1995; Nogueira Neto et al., 1997; Nogueira, 2004). O SGSB, com idade definida em $522 \mathrm{Ma}$, constitui um dos diversos corpos graníticos que intrudiu a porção noroeste do DCC no final do Ciclo Brasiliano. É um corpo multintrusivo, de natureza anorogênica, caracterizado como pós-tectônico. De acordo com sua geoquímica, é classificado como peraluminoso derivado de magma cálcio-alcalino de alto K (Mattos et al., 2007).

O SGSB situa-se no município de Sobral, porção NNW do estado do Ceará (Fig. 1), apresenta forma arredondada do tipo circunscrita e estruturação interna pseudoanelar, de 6 km e extensão de $30 \mathrm{~km}^{2}$ (Mattos, 2005).

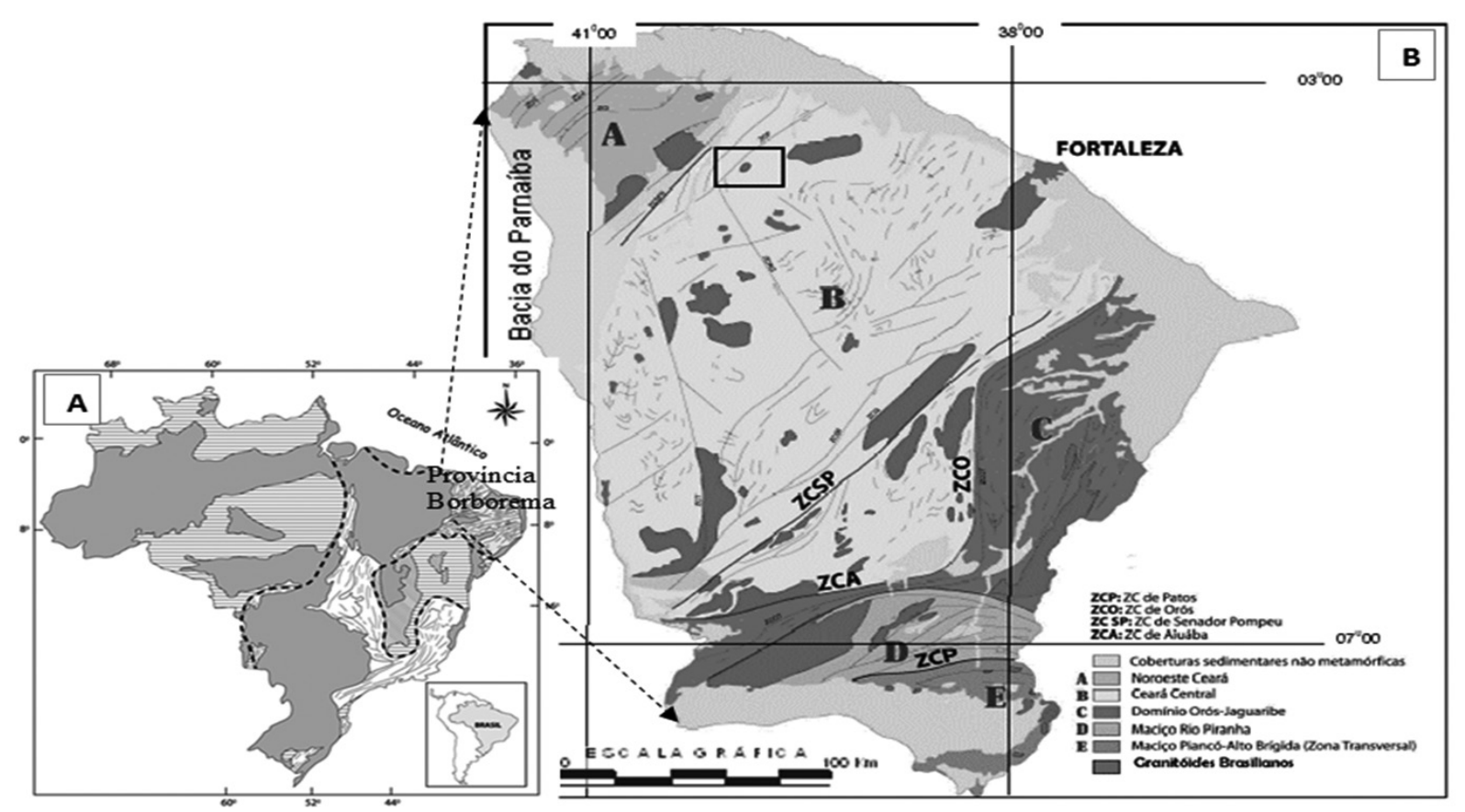

Figura 1. Mapas de localização do SGSB, à NNW da Província Borborema, nordeste do Brasil. A) Mapa baseado em Schobbenhaus \& Campos (1984); B) mapa proposto por Arthaud et al. (1998). No retângulo, a localização do SGSB

Figure 1. Location maps of the SGSB, in the NNW Borborema Province, northeastern Brazil. A) According to Schobbenhaus \& Campos (1984) map; B) proposed by Arthaud et al. (1998) map. In the square, the location of SGSB. 
Há variações faciológicas mapeadas no SGSB interpretadas como devido a características texturais e cromáticas distintas, as quais permitem sua exploração como rocha ornamental (Fig. 2).

O SGSB constitui parte de um evento magmático responsável por diversas intrusões magmáticas (Morrinhos, Pajé, Mucambo, Santa Rosa, entre outros). 0 granito exibe suaves foliações magmáticas na borda do maciço, além de veios aplíticos e xenólitos. Possui textura variando entre inequigranular a porfirítica, localizadamente ocorre textura cumulática e pegmatítica, sendo mais isótropo e homogêneo das bordas para o centro do corpo (Mattos, 2005). É composto por fenocristais idiomórficos de plagioclásio e feldspato alcalino, em meio a uma matriz quartzo-felspática, com biotita, sendo que mica branca, clorita ocorrem como minerais secundários.

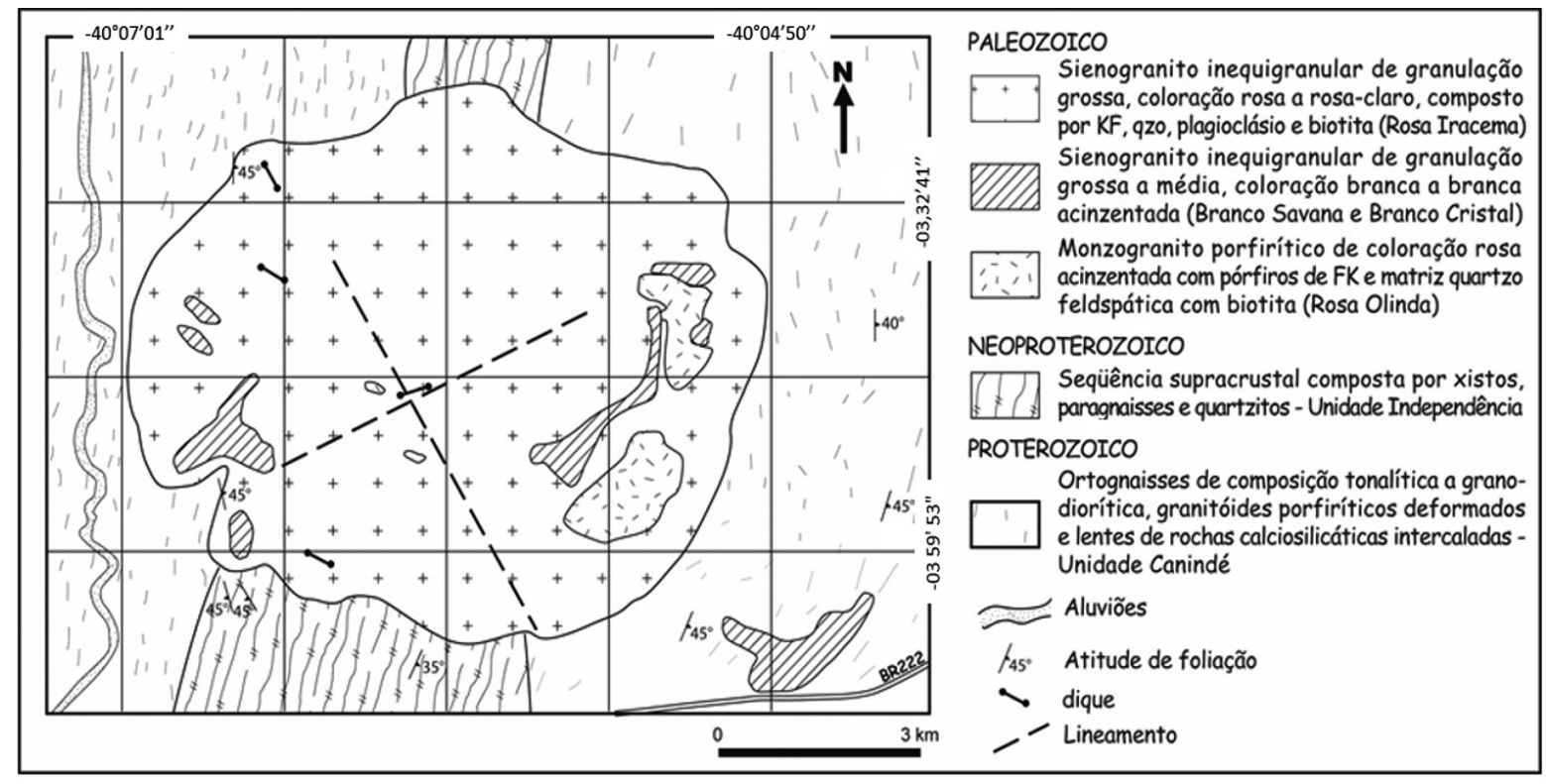

Figura 2. Mapa geológico do SGSB com suas principais variações faciológicas (Coordenadas Geográficas: -03 59’ 53”; -40 07' $\left.01^{\prime \prime}\right)$.

Figure 2. Geological map SGSB with its main facies variations (Geographical coordinates: -03 59' 53"; -40 07' 01").

O SGSB possui variadas texturas e tonalidades resultantes da incorporação de novos pulsos magmáticos, da assimilação de xenólitos da encaixante e também por alterações tardi- a pós-magmáticas. Estas variações compõem diversos tipos faciológicos, de coloração rosa inequigranular, rosa acinzentado porfirítico, rosa claro, rosa pegmatítico, branco porfirítico, branco inequigranular grosso e branco acinzentado de granulação média a grossa. Porém nem todas fácies são passíveis de separação, visto que algumas apresentam limites transicionais e outras não exibem extensão mapeável.

\subsection{Métodos}

Neste trabalho foram selecionados apenas os tipos explorados como rochas ornamentais denominados respectivamente na forma comercial e petrográfica como: Rosa Iracema - sienogranito inequigranular grosso de coloração rosa; Rosa Olinda - monzogranito porfirítico de coloração rosa acinzentada; Branco Savana - sienogranito inequigranular médio a grosso de coloração branca; e Branco Cristal Quartzo - sienogranito inequigranular grosso de coloração branca. Foram desenvolvidos estudos detalhados da composição mineralógica dos quatro tipos faciológicos do SGSB anteriormente descritos, sob os pontos de vista petrográfico e de química mineral.

Os dados foram tratados por meio do software MINPET versão 2.02 (Richard, 1995), para ambiente Windows, contendo métodos para cálculo das fórmulas estruturais dos minerais, bem como diagramas de classificação mineral.

\subsubsection{Análise petrográfica}

Considerando fundamental a análise petrográfica na avaliação do comportamento tecnológico das rochas, foram quantificados os parâmetros composicionais, texturais e estruturais (tamanho, forma, relações de contatos), além de tipos e graus de alteração dos minerais. Para tanto foram tomadas por base as orientações de Rodrigues et al. (1997), Navarro (1998) e da NBR 12.768 (ABNT, 1992).

O tipo e o grau de alteração foram quantificados para plagioclásio (saussuritização, sericitização e epidotização), feldspato potássico (sericitização e formação de argilominerais) e minerais 
máficos (cloritização, epidotização e oxidação). Estas alterações foram classificadas em grau intenso, mais de $60 \%$ da superfície mineral afetado; grau moderado, de 60 a $30 \%$ da superfície com alteração e grau incipiente, com menos de $30 \%$ da superfície mineral com sinais de alteração (Mattos, 2005).

A análise petrográfica seguiu rotina usual, sendo efetuada em microscópio petrográfico binocular Nikon, do Laboratório de Petrografia do Departamento de Geologia da Universidade Federal do Ceará, em 25 lâminas delgadas. Nesta etapa também foi possível identificar os minerais para a análise de química mineral por microssonda eletrônica. Foram captadas 40 imagens e fotomicrografias dos minerais em seis seções delgadas.

\subsubsection{Análise de química mineral}

As análises de química mineral foram obtidas por microssonda eletrônica JEOL (JXA - 8600), do Laboratório de Microscopia e Microssonda Eletrônica do Instituto de Geociências da Universidade de São Paulo. As condições instrumentais de análise foram: potencial de aceleração de $15 \mathrm{Kv}$; cor- rente de amostra de 10nA; diâmetro do feixe eletrônico de $5 \AA$ A. Foram realizadas 141 análises (24 em feldspato potássico, 53 em plagioclásio, 22 em biotita, 26 em clorita, 11 em muscovita e 5 em anfibólio), visando avaliar e comparar a química mineral entre as quatro fácies graníticas do SGSB (Nogueira Neto et al., 2002).

\section{Resultados}

\subsection{Petrografia}

O SGSB possui granulação média a grossa, os minerais são hipidiomórficos: compostos por microclínio, quartzo e plagioclásios (albita e oligoclásio), apresenta como minerais acessórios biotita, hornblenda, apatita, minerais opacos, titanita, allanita e fluorita. Os minerais secundários são sericita, muscovita, clorita, epidoto, carbonatos e argilominerais, além de óxidos e hidróxidos de ferro. As fácies do SGSB correspondem a variedades de sienogranitos e monzogranitos inequigranulares a porfiríticos, com predomínio dos sienogranitos inequigranulares (Fig. 3).

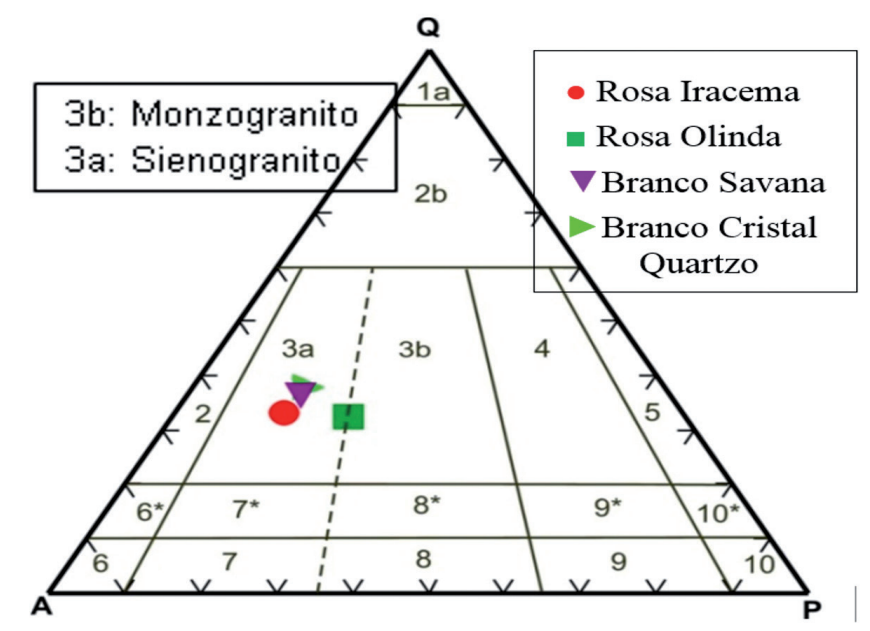

Figura 3. Diagrama modal QAP (nomenclatura e divisão dos campos segundo Streckeisen, 1976).

Figure 3. Modal QAP diagram (nomenclature and division of fields according to Streckeisen, 1976).

São comuns variações nas dimensões e concentrações de feldspatos e quartzo, modificando não só a textura, de inequigranular para porfirítica (até feições pegmatíticas localizadas), como também a coloração, que modifica de rosa para rosa claro e de branco para branco acinzentado. As principais variações entre as fácies estudadas estão resumidas na tabela 1 .

\subsection{Química Mineral}

Considerando as quatro facies petrográficas, as análises químicas de algumas fases foram rea- lizadas nos minerais mais instáveis, como biotita, muscovita, clorita, anfibólio e feldspato. Os cálculos das fórmulas estruturais obedecem aos parâmetros: biotita - base de 24 oxigênios (Deer et al., 1992); muscovita - 22 oxigênios; clorita - 36 oxigênios; anfibólio - 15 cátions e 23 oxigênios (Robinson et al., 1981) e feldspatos - base de 32 oxigênios (Deer et al., 1992).

0 resultado das análises permitiu relacionar a concentração química (com respectivos valores mínimos e máximos) dos elementos formadores dos minerais constituintes de cada fácies. Alguns diagramas foram selecionados visando enquadrar 
e determinar a classificação dos minerais. Parte dos resultados obtidos anteriormente por Nogueira Neto et al. (2002) permitiu uma análise de felds- pato, clorita, biotita e anfibólio das facies Sienogranito Médio-Grosso (BS) e Sienogranito Grosso (RI).

Tabela 1. Síntese das características petrográficas dos quatro tipos graníticos ornamentais do SGSB.

Table 1. Summary of petrographic characteristics of the four ornamental granite types from SGSB.

\begin{tabular}{|c|c|c|c|c|c|}
\hline \multicolumn{2}{|c|}{$\begin{array}{l}\text { CARACTERÍSTICAS } \\
\text { PETROGRÁEICAS }\end{array}$} & ROSA IRACEMA & ROSA OLINDA & BRANCO SAVANA & $\begin{array}{c}\text { BRANCO CRISTAL } \\
\text { QUARTZO } \\
\end{array}$ \\
\hline \multicolumn{2}{|c|}{ Coloração } & Rosa a Rosa claro & $\begin{array}{c}\text { Rosa } \\
\text { acinzentado }\end{array}$ & $\begin{array}{c}\text { Branco } \\
\text { acinzentado }\end{array}$ & Branco acinzentado \\
\hline \multicolumn{2}{|l|}{ Estrutura } & Isotrópica & Isotrópica & Isotrópica & Isotrópica \\
\hline \multicolumn{2}{|l|}{ Textura } & Inequigranular & Porfirítico serial & Inequigranular & Inequigranular \\
\hline \multicolumn{2}{|l|}{ Granulação } & Média-Grossa & $\begin{array}{l}\text { Média-Grossa } \\
\text { (matriz) }\end{array}$ & Média a Grossa & Média-Grossa \\
\hline \multicolumn{2}{|c|}{ Quartzo } & 30,0 & 28,0 & 34,0 & 35,0 \\
\hline \multicolumn{2}{|c|}{ Feldspato potásico } & 43,0 & 36,0 & 43,0 & 40,0 \\
\hline \multicolumn{2}{|c|}{ Albita } & 4,5 & 2,2 & 2,0 & 3,0 \\
\hline \multicolumn{2}{|c|}{ Oligoclásio } & 13,0 & 19,8 & 14,0 & 14,0 \\
\hline \multicolumn{2}{|c|}{ Biotita } & 6,0 & 10,0 & 5,0 & 4,0 \\
\hline \multicolumn{2}{|c|}{ Hornblenda } & 0,5 & 0,5 & - & - \\
\hline \multicolumn{2}{|c|}{ titanita, apatita, zircão, } & 1,0 & 2,0 & 0,5 & 1,0 \\
\hline \multicolumn{2}{|c|}{$\begin{array}{l}\text { fluorita, clorita, muscov., } \\
\text { sericita, argilomin., epidoto, } \\
\text { carbonatos, óxido/hidr. } \\
\text { ferro }\end{array}$} & 2,0 & 1,5 & 1,0 & 2,5 \\
\hline \multicolumn{2}{|c|}{ Total minerais máficos (\%) } & 7,5 & 13,0 & 7,0 & 8,0 \\
\hline \multirow{2}{*}{$\begin{array}{l}\text { Granulação } \\
\text { (mm) }\end{array}$} & Variação & 0,3 a 40 & 0,2 a 30 & 0,3 a 15 & 0,4 a 30 \\
\hline & Predominância & 5 a 15 & 7 a 20 & 3 a 6 & 4 a 8 \\
\hline \multirow{3}{*}{$\begin{array}{l}\text { Alteração } \\
\text { Mineral }\end{array}$} & Feldspato K & Baixo/ Moderado & Baixo & Moderado & Moderado \\
\hline & Plagioclásio & Moderado & Baixo & Moderado & Moderado \\
\hline & Biotita & Moderado/alto & Baixo & Moderado/alto & Moderado/alto \\
\hline \multicolumn{2}{|c|}{ Classificação Petrográfica } & $\begin{array}{l}\text { Sienogranito } \\
\text { inequigranular } \\
\text { grosso }\end{array}$ & $\begin{array}{l}\text { Biotita } \\
\text { monzogranito } \\
\text { porfirítico }\end{array}$ & $\begin{array}{l}\text { Sienogranito } \\
\text { inequigranular } \\
\text { médio-grosso }\end{array}$ & $\begin{array}{l}\text { Sienogranito } \\
\text { inequigranular } \\
\text { grosso }\end{array}$ \\
\hline
\end{tabular}

3.2.1 Sienogranito inequigranular grosso - Rosa Iracema (Ri)

Os feldspatos apresentam alterações para minerais de argila, micas brancas ou epidoto, que registram a ocorrência de eventos hidrotermais e/ou tardi-magmáticos, visto que em ambiências ricas em alumínio, sericita e muscovita podem ser geradas às expensas de plagioclásio e feldspato potássico (Nogueira Neto et al., 2002).

Considerando os termos extremos da solução sólida Ab-An-Or (Deer et al., 1992), os feldspatos potássicos possuem albita variando entre 4,1 até $8,9($ Ab 4,1 - 8,9) e ortoclásio entre 91,1 até 95,8 (Or 91,1 - 95,8) cuja fórmula estrutural na base de 32 oxigênios, corresponde a: $\mathrm{Na}(0,0405-0,088)$, $\mathrm{K}(0,904-0,957)$ [Al $(0,986-0,990)$ Si $(3,005-$ $3,009)] \mathrm{O}_{8}$ (Fig. 4A e 4B).
Os plagioclásios exibem proporção de albita entre 71,5 a 96,3 (Ab 71,5 - 96,3) e anortita de 0,8 até $15,8(\mathrm{Na} 0,8-15,8)$, posicionando os plagioclásios entre os termos albita - oligoclásio, com a seguinte composição: Na $(0,177$ - 0,940), Ca $(0,008$ - 0,039), K (0,004 - 1,100) [Al $(1,000-1,140) \mathrm{Si}$ $(2,854-2,998)] \mathrm{O}_{8}$ (Fig. 4A e 4B).

A biotita apresenta fórmula química com as seguintes proporções: $\mathrm{K}(1,744-1,983) \mathrm{Na}(0,030$ - 0,023) Ca $(0,000$ - 0,013) (Mn $(0,056$ - 0,079) Ba $(0,000-0,009) \mathrm{Mg}(0,319-0,553), \mathrm{Fe}^{+2}(4,479$ - 4,995) $\left(\mathrm{Fe}^{3}+, \mathrm{Al}^{\mathrm{VI}}(0,463-1,120)\right.$, Ti $(0,286-$ $0,431)\left[\operatorname{Si}(5,651-5,946) \mathrm{Al}^{\mathrm{IV}}(2,054-2,349)\right] \mathrm{O}_{20}$ $(\mathrm{OH}, \mathrm{F})_{4}$.

A biotita tem razões $\mathrm{Fe} /(\mathrm{Fe}+\mathrm{Mg})$ que variam entre 0,80 e 0,93, situando-a no campo da annita conforme o diagrama de classificação $\mathrm{Al}^{\mathrm{VI}}$ versus $\mathrm{Fe} /(\mathrm{Fe}+\mathrm{Mg})$, segundo Deer et al. (1992) na solução 
flogopita-annita-eastonita-siderofilita (Fig. 5).

Na biotita com hábito lamelar ocorre evidente transformação para clorita, como uma pseudomorfose: o pleocroismo típico de biotita passa a ser substituído por um pleocroismo de cor verde escuro a amarelado, contudo a forma e a estrutura original da biotita apresentam-se conservadas. A transformação da biotita para muscovita é evidenciada também pela alteração do pleocroísmo de tonalidades marrons para incolor ou amarelo pálido.

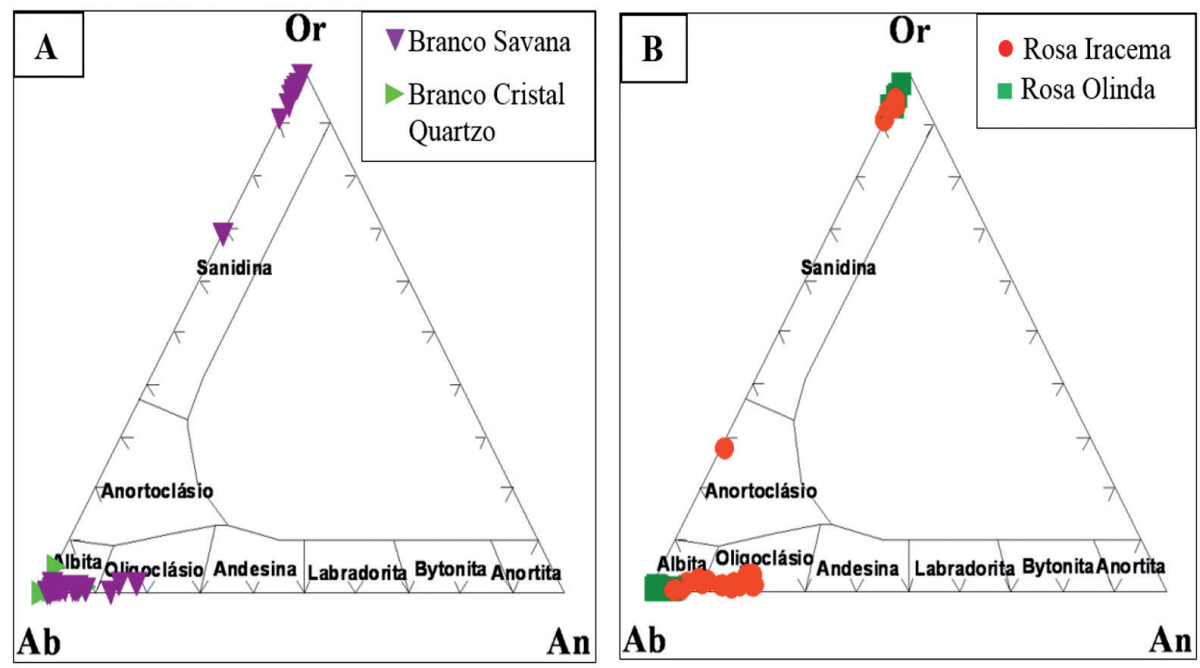

Figura 4. Diagrama ternário segundo Deer et al. (1992) de classificação de feldspatos. O plagioclásio do SGSB é albita (Ab71-96) enquanto o feldspato alcalino corresponde à ortoclásio (Or91-98). A) Variação da composição dos plagioclásios dos tipos rosas. B) Variação da composição dos plagioclásios dos tipos brancos, entre albita e oligoclásio, indicando maior quantidade de cálcio. Figure 4. Ternary diagram according to Deer et al. (1992) of feldspar classification. Plagioclase of SGSB is albite (Ab71-96) while the alkali feldspar corresponds to orthoclase (Or91-98). A) Variation in the plagioclase composition of the pink types. B) Variation in the plagioclase composition of the white types, between albite and oligoclase, indicating greater amount of calcium in plagioclases.

Em resposta aos processos de transformação e reequilíbrio, são formadas também lamelas de muscovita, argilominerais e, mais comumente, clorita.

No SGSB a clorita é produto da transformação das biotitas e apresentam-se muito semelhantes às estas na forma, contudo, apresentam pleocroísmo verde e possuem fórmula química dada por: $\mathrm{K}(0,001-0,997) \mathrm{Ca}(0,00-0,042) \mathrm{Na}(0,000-$ $0,032) \mathrm{Mg}(0,015-0,214) \mathrm{Fe}^{+2}(6,41-8,65), \mathrm{Mn}$ $(0,098-0,120)$, Ti $(0,00-0,162) \mathrm{Al}^{\mathrm{VI}}(2,49-3,41)$ $\left[\left(\mathrm{Si}(5,02-6,58) \mathrm{Al}^{\mathrm{IV}}(1,54-2,980)\right] \mathrm{O}_{20}(\mathrm{OH})_{16}\right.$.

No diagrama de classificação de clorita de acordo com Deer et al. (1992) $\mathrm{Fe}_{\text {total }}$ versus $\mathrm{Si}$, as cloritas estudadas caem no campo da Dafinita, comportamento válido tanto para o sienogranito inequigranular grosso (RI) como para os outros termos faciológicos do corpo (Fig. 6).

0 anfibólio exibe cor verde escura, é hornblenda com pleocroísmo verde acastanhado e ocorre em pequenas quantidades. Foram analisados apenas nas fácies sienogranito inequigranular grosso (RI), sendo que a fórmula química corresponde a: K $(0,253$ - 0,287), Na $(0,507-0,668)$, Ca $(1,696-$ 1,787) (Mg $(0,721-0,922), M n(0,032-0,045), \mathrm{Ti}$ $(0,115-0,233), \mathrm{Fe}^{3+}(0,200-0,316), \mathrm{Fe}^{2+}(3,181-$ $3,433))[S i(6,519-6,611)$ Al $(1,683-1,866)] \mathrm{O}_{22}$ $(\mathrm{OH})_{2}$.
Através do diagrama de $\mathrm{Mg} / \mathrm{Mg}+\mathrm{Fe}^{2+}$ contra $\mathrm{Si}$ de Leake et al. (1997), este anfibólio é classificado como hornblenda ferroedenita (Fig. 7). A hornblenda típica das rochas das séries cálcio-alcalinas tem relação $\mathrm{Mg}: \mathrm{Fe}^{2+}$ de 1:1 e teor de $\mathrm{Al}$ próximo a 1,5 (Deer et al., 1992). No sienogranito inequigranular grosso (RI) a proporção de $\mathrm{Mg}: \mathrm{Fe}^{2+}$ é de aproximadamente $1: 3$, representando variações de com elevado teor de $\mathrm{Fe}^{2+}$ e quantidade de alumínio relativamente maior, atingindo até 1,9 Al.

\subsubsection{Monzogranito porfirítico - Rosa Olinda (RO)}

0 monzogranito porfirítico mostra semelhança mineralógica com o sienogranito inequigranular grosso (RI), indicada pela composição modal em ambas as facies graníticas. Assim, seu comportamento químico apresenta-se coerente com a análise petrográfica, confirmando a composição química de seus minerais constituintes, com exceção em alguns casos onde ocorrem reações de alteração e substituição dos minerais.

0 feldspato alcalino, nos termos extremos da solução sólida Ab-An-Or, apresenta Ab $(2,2$ - 6,5) Or $(93,5$ - 97,8), correspondendo a seguinte fórmula estrutural: $\mathrm{Na}(0,022-0,050) \mathrm{K}(0,653-0,959)$ [Al $(0,984-1,010) \mathrm{Si}(2,232-3,054)] \mathrm{O}_{8}$.

Os plagioclásios por sua vez exibem Ab $(95,1$ 
- 98,3) Na (1,0 - 4,1), e composição química como: $\mathrm{Na}(0,928-0,980)$, Ca $(0,010-0,040)[\mathrm{Al}(0,998-$ 1,013) Si $(2,984-3.000)] 0^{8}$.

Conforme os valores mostrados acima, o plagioclásio é essencialmente albita e a maioria do feldspato potássico é ortoclásio (Fig. 4A).

A clorita também é originada pela transfor- mação da biotita primária, e apresenta pleocroísmo verde escuro. A fórmula química determinada foi: $\mathrm{Mg}(1,220-1,831), \mathrm{Fe}^{+2}(7,587-7,767), \mathrm{Mn}$ $(0,141-0,214), \mathrm{Al}^{\mathrm{VI}}(2,524-2,843)$ [ (Si $(5,305-$ $\left.\left.5,462) \mathrm{Al}^{\mathrm{IV}}(2,538-2,713)\right)\right] \mathrm{O}_{20}(\mathrm{OH})_{16}$. Esta composição classifica a clorita como dafinita (Fig. 6).

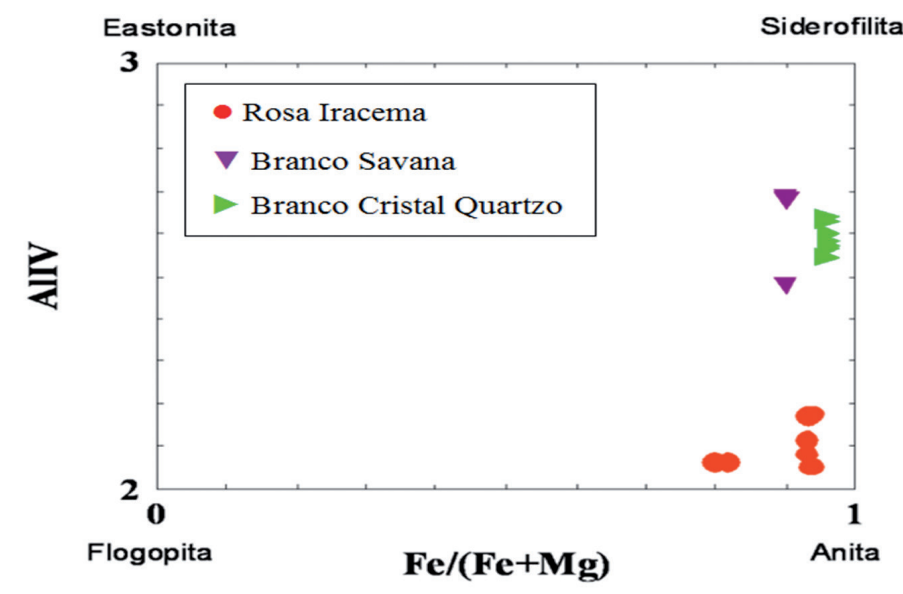

Figura 5. Diagrama de classificação da biotita de acordo com Deer et al. (1992). Nos granitos Rosa Iracema, Branco Cristal Quartzo e Branco Savana corresponde à annita na solução flogopita-annita-eastonita -siderofilita, com $\mathrm{Fe} /(\mathrm{Fe}+\mathrm{Mg})$ variando entre 0,80 e 0,96 .

Figure 5. Diagram of biotite classification according to Deer et al. (1992). Biotite from the Iracema, Branco Cristal Quartz and Branco Savana granites corresponds to Annita in phlogopite-annite-eastonite-siderofilite solution, with $\mathrm{Fe} /(\mathrm{Fe}+\mathrm{Mg})$ between 0.80 and 0.96 .

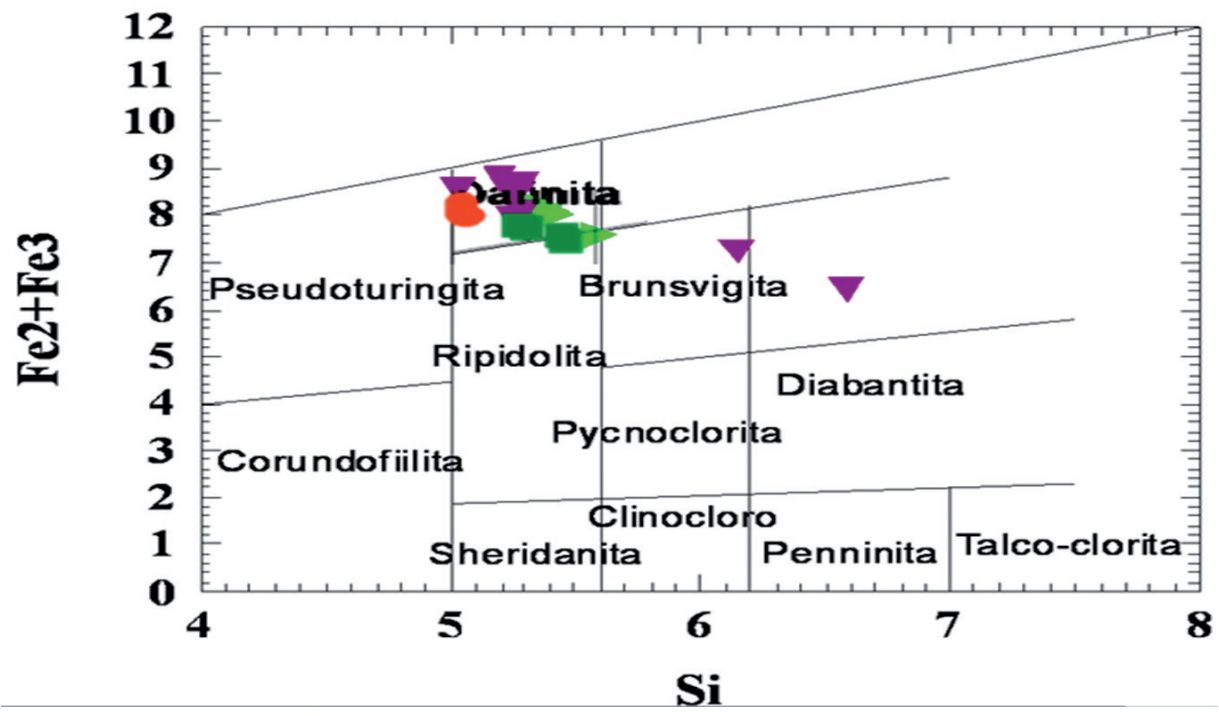

Figura 6. Diagrama de classificação da clorita segundo Deer et al. (1992). Nos quatro tipos graníticos a clorita corresponde a dafinita, com algumas exceções no granito Branco Savana, com Fe total variando entre 6,41 e 8,65.

Figure 6. Diagram of chlorite classification according Deer et al. (1992). In the four granite types, chlorite corresponds to dafinite, with some exceptions in granite Branco Savana, with total Fe ranging between 6.41 and 8.65 .

A muscovita é secundária, proveniente de alterações dos feldspatos alcalinos e da biotita e fornecem a seguinte fórmula química: $\mathrm{K}(1,520$ 1,771) AlVI 2,198-2,730 [ (Si 5,553 -5,878 AlIV 2,122 - 2,447) ] $\mathrm{O}^{20}(\mathrm{OH}, \mathrm{F})^{2}$.

Ocorre uma ligeira diferença entre a composição da muscovita no monzogranito porfirítico (RO) devido ao tipo de substituição. A muscovita que substitui parte do feldspato potássico é mais rica em $\mathrm{K}$ e $\mathrm{Al}$ e menos rica em $\mathrm{Fe}$, quando comparada com a muscovita oriunda da substituição da biotita, conforme observado no diagrama da figura 8.

3.2.3 Sienogranito inequigranular médio-grosso Branco Savana (BS)

A composição química obtida para os feldspa- 
tos alcalinos registram os termos $\mathrm{Ab}(0,7-31,1)$ Or $(68,7-99,3)$, com a seguinte fórmula química: Na $(0,008-0,305) \mathrm{K}(0,675-0,975)[\operatorname{Si}(2,986-$ 3.014) $\mathrm{Al}(0.982-1.015)] \mathrm{O}_{8}$. Os plagioclásios têm composições Ab (91,4 -
98,7) An $(0,0$ - 7,9), considerando os termos extremos da solução sólida Ab-An-Or. A composição química corresponde a: Na $(0,899-0,967)$ Ca $(0,001$ $-0,076)[\mathrm{Si}(2,922-3,010) \mathrm{Al}(0,986-1,079)] \mathrm{O}_{8}$.

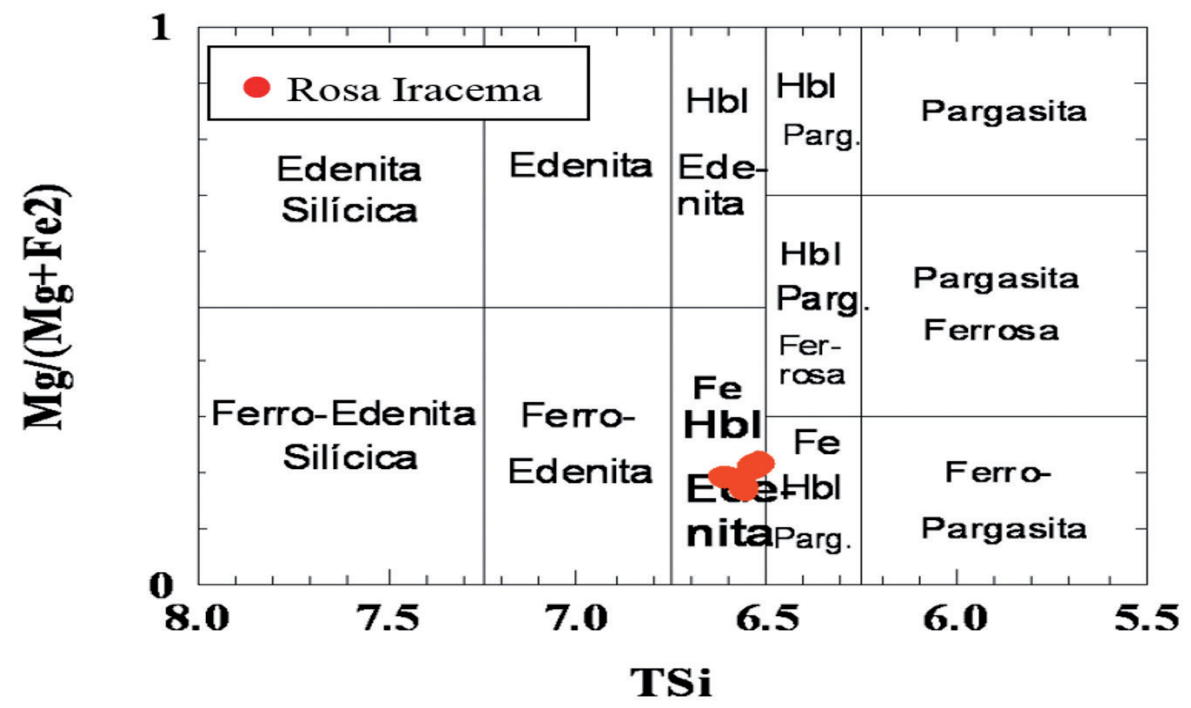

Figura 7. Diagrama de classificação de anfibólio [Mg/(Mg+Fe) x TSi] (Leake et al., 1997) para o granito Rosa Iracema, mostrando que o anfibólio analisado é hornblenda Fe-edenita. A edenita é um anfibólio cálcico derivado da hornblenda pela adição de Na e substituição do Al pelo Si.

Figure 7. Classification diagram of amphibole $[\mathrm{Mg} /(\mathrm{Mg}+\mathrm{Fe}) \times \mathrm{TSi}]$ (Leake et al.,1997) to Rosa Iracema granite, demonstrate that the analyzed amphibole is Fe-edenite hornblende. The edenite is a calcium amphibole derived from hornblende by the addition of Na and replacement of Al by Si.

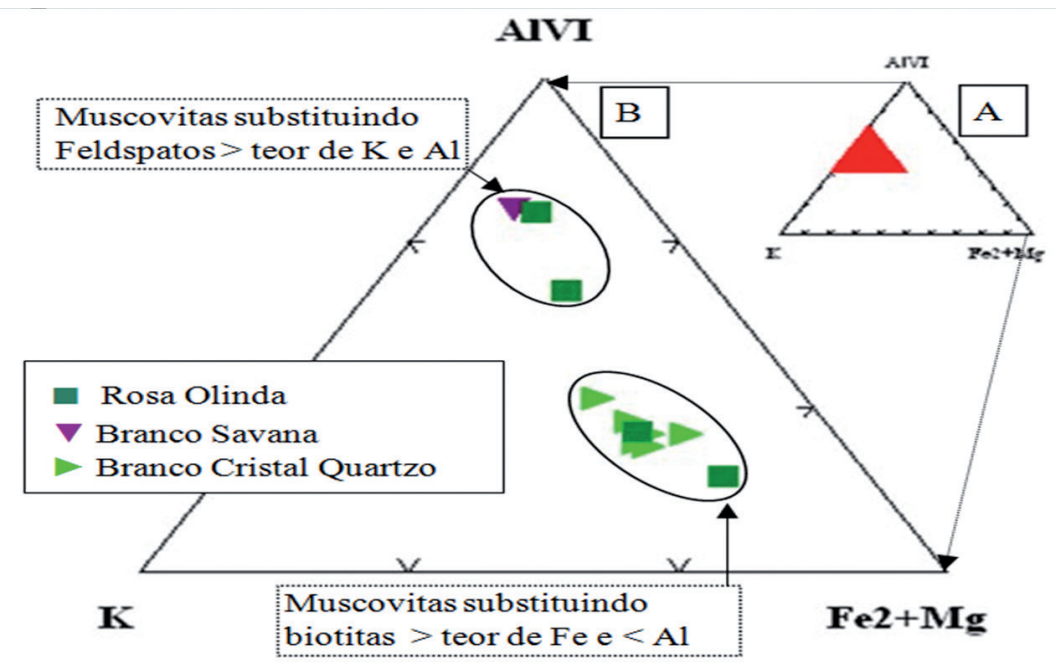

Figura 8. Diagrama de $\mathrm{Al}^{\mathrm{vI}}-\mathrm{K}-\mathrm{Fe}^{2+}+\mathrm{Mg}$ para muscovita dos Granitos Rosa Olinda, Branco Cristal Quartzo. A) Área do diagrama a ser detalhado; B) Diagrama ampliado exibindo duas populações: muscovita formada em feldspatos (mais enriquecidas em $\mathrm{K}$ e $\mathrm{Al}$ ) e muscovita formada em biotita (mais enriquecidas em $\mathrm{Fe}$ ).

Figure 8. $\mathrm{Al}^{V I}-\mathrm{K}-\mathrm{Fe}^{2+}+\mathrm{Mg}$ diagram for muscovite from the Rosa Olinda and Branco Quartz Cristal Granites. A) Diagram area to be detailed; B) Expanded diagram exhibiting two populations: muscovite formed after feldspars (more enriched in K and Al) and muscovite formed after biotite (more enriched in $\mathrm{Fe}$ ).

Assim, de forma similar aos plagioclásios do sienogranito inequigranular grosso (RI), os plagioclásios variam de albita até oligoclásio, enquanto o feldspato alcalino, em sua grande maioria, tem composição de ortoclásio (Fig. 4B).

Os plagioclásios possuem maior susceptibilidade a processos de albitização de suas bordas, quando em contato com cristal de microclínio, as- sociado a mirmequitas e cristais intergranulares de feldspato potássico.

A biotita apresenta razões $\mathrm{Fe} /[\mathrm{Fe}+\mathrm{Mg}]$ entre 0,82 a 0,90 , e é classificada como annita, com leve tendência ao campo da siderofilita, pelo maior teor de $\mathrm{Al}^{\mathrm{IV}}(2,35)$ (Fig. 5). 0 forte pleocroísmo, de avermelhado à marrom escuro, está relacionado com a presença do Fe e/ou Ti na composição. 0 pleocro- 
ísmo é modificado quando ocorre alteração da biotita para clorita, tornando-se esverdeado ou verde escuro em lamelas totalmente substituídas.

A clorita é formada a partir da biotita primária, ocorrendo nas bordas e nos planos de clivagens da biotita. Esta clorita demonstra certa variação em sua classificação, disposta entre os termos dafinita e burnsvigita (Fig. 6). Ocorrem na seguinte composição: K $(0,004-0,997) \mathrm{Ca}(0,000-0,042)$ Na $(0,002-0,015)$ (Mn $(0,110-0,158), \operatorname{Mg}(0,169$ $-0,266), \mathrm{Fe}^{+2}(6,409-8,607)\left(\mathrm{Al}^{\mathrm{IV}}(1,415-2,802)\right.$, $\mathrm{Ti}(0,000-0,133))\left[\mathrm{Si}(5,198-6,586) \mathrm{Al}^{\mathrm{VI}}(2,870-\right.$ $3,413)] \mathrm{O}^{20}(\mathrm{OH})^{16}$.

\subsubsection{Sienogranito inequigranular grosso - Branco Cristal Quartzo (BCQ)}

Como nas fácies anteriormente descritas, os feldspatos geralmente estão alterados para minerais de argila e micas. 0 feldspato potássico apresenta $\mathrm{Ab}(4,02)$ Or $(95,98)$, correspondendo à fórmula estrutural: Na $(0,041)$ K $(0,991)$ [Si $(2,986)$ $\mathrm{Al}(1,002)] 0^{8}$.

Os plagioclásios possuem relação $\mathrm{Ab}(95,1$ $98,3)$ e An $(1,0$ - 4,1), cuja composição química é dada por: $\mathrm{Na}(0,696-1,418), \mathrm{Ca}(0,000-0,061)$ [Si $(2,921-3.029) \mathrm{Al}(0,963-1,069)] 0^{8}$. 0 plagioclásio é essencialmente albítico e o feldspato potássico têm composição de ortoclásio (Fig. 4B).

A biotita comporta-se quimicamente de forma semelhante àquelas do sienogranito inequigranular médio-grosso (Branco Savana) e ao sienogranito inequigranular grosso (Rosa Iracema) apresentando as razões $\mathrm{Fe} /[\mathrm{Fe}+\mathrm{Mg}]$, em torno de 0,96 , segundo a classificação, também se encontra no campo da annita, pelo teor de $\mathrm{Al}^{\mathrm{IV}}$ (Fig. 5).

Assim como nas outras fácies graníticas, a clorita provém da transformação da biotita. No sienogranito inequigranular grosso é classificada como Dafinita (Fig. 6) e possui fórmula química dada por: $\mathrm{Mg}(0,256-0,298) \mathrm{Fe}^{+2}(7,584-8,165), \mathrm{Mn}$ $(0,0121-0,184), \mathrm{Al}^{\mathrm{VI}}(3,118-3,373)[(\mathrm{Si}(5,372-$ $\left.5,597) \mathrm{Al}^{\mathrm{IV}}(2,403-2,728)\right] \mathrm{O}^{20}(\mathrm{OH})^{16}$.

A muscovita está presente nos tipos sienogranito inequigranular médio-grosso (BS) e sienogranito inequigranular grosso (BCQ) como mineral secundário, formado a partir da substituição da biotita primária instável e da alteração dos feldspatos, através de reações tardi- a pós-magmáticas ou hidrotermais. Apresenta a seguinte fórmula química: $\mathrm{K}(1,706$ - 1,809) Ca $(0,000-0,003)$ e $\mathrm{Na}(0,058-0,098)\left(\mathrm{Al}^{\mathrm{VI}}(2,299-2,393)\right.$, Ti $(0,003$ - 0,024), $\mathrm{Fe}^{+2}(0,133-0,147), \mathrm{Mn}(0,000-0,004)$, $\operatorname{Mg}(0,002-0,186))\left[\operatorname{Si~}(5,622-5,792) \mathrm{Al}^{\mathrm{IV}}(2,176-\right.$ $2,378)] \mathrm{O}^{20}(\mathrm{OH})^{16}$.
Os elementos $\mathrm{Ti}, \mathrm{Fe}, \mathrm{Mn}, \mathrm{Mg}$, $\mathrm{Ca}$ e $\mathrm{Na}$, encontrados nesta muscovita, mostram que sua origem provavelmente se deu a partir da transformação de biotita, visto que na fórmula química das muscovitas estes elementos estão ausentes (Fig. 8).

\section{Discussão dos resultados}

As alterações geoquímicas em nível mineral são consequências de reações tardi- a pós-magmáticas, geralmente associadas à transformação, substituição e/ou neoformação de minerais. Estas transformações podem estar relacionadas a fluidos do próprio magma que não entraram na estrutura dos minerais primários ou com fluidos hidrotermais tardios, os quais, ora enriquecidos em determinados elementos, ora carreando outros, modificaram a associação mineral original da rocha.

As condições físico-químicas do meio fluido, tais como, $\mathrm{pH}$, Eh, temperatura, pressão, fugacidade de oxigênio, permeabilidade e porosidade da rocha, e arranjo mineralógico são fatores que determinam a mobilidade e as reações químicas dos elementos. A investigação criteriosa destas reações de caráter tardio ou pós-magmático auxiliou na determinação das condições de transformação dos minerais de alteração do SGSB.

Transformações minerais pós-magmáticas como exsolução (pertitização, formação de mirmequitas), potassificação, sericitização, albitização, neoformação de fluorita e cloritização são comumente encontradas no SGSB.

Segundo Phillips (1974), as mirmequitas são formadas por reações tardi-magmáticas que envolvem interação entre substituição e exsolução química em minerais de composições alcalinas, representadas por feldspatos de $\mathrm{Ca}, \mathrm{Na}$ e K. Estas reações são comumente encontradas em granitos pós-tectônicos não deformados, que possuam natureza cálcio-alcalina, ocorrendo também no SGSB. As reações de formação das mirmequitas são mais frequentes nas porções pegmatíticas e nas margens do SGSB, presentes principalmente nas bordas de cristais de feldspatos potássicos, em forma de "franjas" caracterizadas como reações de exsolução.

As transformações de substituição por processos de potassificação ocorrem pela neoformação de biotita e/ou K-feldspato, notadamente ortoclásio, mas se dá também pela geração de microclínio tardio (microclinização), na qual esta alteração pervasiva gera na rocha uma coloração avermelhada/rosada ou esbranquiçada, geralmente perdendo grande parte dos seus minerais ferro- 
-magnesianos através dos processos hidrotermais. A paragênese encontrada pode ser: K-feldspato + biotita + sericita + clorita + quartzo.

Reações de microclinização nas facies brancas das rochas estudadas (BS e BCQ) são bastante comuns e ocorrem sombras de maclas de albita sobre a reação de microclinização do plagioclásio. Os cristais apresentam-se bem mais límpidos quando comparados com as alterações de argilo minerais e óxidos de ferro dos feldspatos potássicos e plagioclásios.

Também denominado sericitização ou muscovitização, o processo de transformação dos feldspatos em mica branca se dá pela transformação parcial ou total dos referidos minerais, bem como da biotita, com geração de muscovita, sericita e argilo minerais. A reação de muscovitização nos granitos da Serra do Barriga é a alteração mais frequente e parece ser a segunda mais tardia (argilização é mais tardia), sendo que pertencem à mesma fase de formação da clorita e do epidoto, pois ocorre sobre feldspatos e biotita. A formação de sericita e muscovita é mais intensa no plagioclásio, provavelmente devido às reações de microclinização neste, quando comparada com feldspato potássico, estando também presente em biotita. De modo geral, os granitos brancos mostram-se mais afetados pela sericitização e muscovitização que as faciologias rosadas (RI e RO) (Tab. 1).

A albitização está estreitamente associada à microclinização nas fases iniciais do hidrotermalismo de granitos evoluídos. São indícios deste processo a descalcificação dos plagioclásios, a albitização dos feldspatos potássicos, a neoformação de albita em mirmequitas e/ou pertitas e o reequilíbrio das micas. Pode ser representada pela paragênese: albita + feldspato potássico + biotita + fluorita (Deer et al., 1992). A albitização ocorre nas interfaces (contatos) entre cristais de plagioclásio e de microclínio, em geral associados com mirmequitas, e de forma intergranular, principalmente entre cristais de feldspato potássico. A albitização em torno dos cristais de feldspatos potássicos e neoformação de albita em pertitas ou inclusas no feldspato potássico são texturas comuns no SGSB.

Ocorrem reações de neoformação de fluorita, mineral indicativo de transformações tardi-magmáticas e dos fenômenos sobre mineralizações, também mais abundante nos processos hidrotermais dos sistemas a Greisen que nos sistemas Pórfiros. Ocorre como mineral acessório bastante comum em pegmatitos, granitos e sienitos, frequentemente associado a outros minerais hidrotermais (Deer et al., 1992). As reações de neoformação de fluorita no SGSB ocorrem nos granitos brancos (BS e BCQ) e geralmente se apresentam na forma de grãos intersticiais associados a cristais de biotita.

0 processo de cloritização se deve principalmente à transformação da biotita, produzindo um forte pleocroísmo de coloração verde intenso desenvolvido mais frequentemente quando ocorre maior disponibilidade de alumínio (Deer et al., 1992). Apesar da cloritização parcial da biotita ocorrer nas quatro fácies, mostra-se mais frequente nas fácies brancas (BS e BCQ). A clorita apresenta uma pseudomorfose com a biotita, a qual ainda preserva sua forma, embora a composição e as características petrográficas sejam claramente de clorita.

\section{Conclusões}

Os minerais constituintes do SGSB demonstram que apesar das variações texturais e cromáticas entre si é possível determinar três fácies (RI, BS, BCQ) sienograníticas devido ao percentual em feldspato alcalino muito maior que a facie monzogranítica (RO), ocorrendo o inverso com relação ao conteúdo de quartzo e biotita. Esta última facie mostra menor influência de alteração hidrotermal. São comuns variações nas dimensões e concentrações de feldspatos e quartzo, modificando não só a textura, de inequigranular para porfirítica (até feições pegmatoides localizadas), como também a coloração, que modifica de rosa para rosa claro e de branca para branca acinzentada.

As análises químicas de biotita também demonstram composições muito pouco variadas entre as fácies graníticas, porém no Sienogranito inequigranular médio-grosso e no grosso (BS e BCQ) a biotita por mostrar razões de $\mathrm{Al}^{\mathrm{IV}}$ maiores que no Sienogranito inequigranular grosso (RI) apresenta um deslocamento no diagrama de classificação do campo da annita para o da siderolifita.

As transformações tardias como microclinização geram na rocha coloração esbranquiçada, geralmente perdendo grande parte dos seus minerais ferro-magnesianos através dos processos hidrotermais. 0 efeito cromático rosa do sienogranito inequigranular grosso (RI) está associado ao menor grau de muscovitização e sericitização, maior proporção de feldspato potássico, composição mais rica em Fe (biotita e clorita) e maior quantidade de minerais máficos. Nos granitos brancos são mais frequentes as reações de sericitização no plagioclásio sobreposta à microclinização, além de neoformação de fluorita.

As transformações minerais pós-magmáticas ou hidrotermais como exsolução, potassificação, 
albitização, cloritização (a clorita é dafinita), sericitização e neoformação de fluorita são frequentes no SGSB e contribuem na "descoloração" das facies rosadas para as esbranquiçadas (BS e BCQ).

Os estudos petrográficos e de química mineral, além de determinar a paragênse mineral e as reações minerais tardi- a pós-magmáticas entre as faciologias analisadas, indicam que o SGSB foi formado por um mesmo evento magmático. Os Sienogranitos (RI, BS e BCQ) correspondem a faciologias originadas por processos de fracionamento, acrescidas por pulso magmático de composição mais máfica representado pelo Monzogranito porfirítico (RO) conforme demonstrado pela análise petrográfica.

Agradecimentos. Os autores agradecem ao CNPq pelo apoio financeiro, através do processo $\mathrm{N}^{\circ} 141388 / 2002$ 1 (Bolsa de Formação de Pesquisador Doutorado), que tornou possível a realização deste trabalho.

\section{Referências}

ABNT. Associação Brasileira de Normas Técnicas. 1992. NBR 12768, Rochas para Revestimento - Análise Petrográfica. Rio de Janeiro, ABNT, 3p.

Almeida, A.R. 1995. Petrologia e aspectos tectônicos do Complexo Granítico Quixadá - Quixeramobim, CE. São Paulo, 279p. Tese de Doutorado, Programa de Pós-graduação em Geoquímica e Geotectônica, Instituto de Geociências, Universidade de São Paulo.

Arthaud, M.H., Vasconcelos, A.M., Nogueira Neto, J.A., Oliveira, F.V.C., Parente, C.V., Monié, P., Liegeois, J.T., Caby, R. \& Fetter, A. 1998. Main structural features of Precambrian domains from Ceará (NE Brazil). In: INTERNATIONAL CONFERENCE ON BASEMENT TECTONICS, 14., 1998, Ouro Preto. Abstracts... Ouro Preto, UFOP, p. 84-85.

Deer, W.A., Howie, R.A. \& Zussman, J. 1992. Minerais Constituintes das Rochas - Uma Introdução. Lisboa, Fundação Calouste Gulbenkian, 696p.

Leake, B.E., Schumacher, J.C., Smith, D.C., Ungaretti, L., Whittaker, E.J.W. \& Youzhi, G. 1997. Nomenclature of amphiboles. European Journal of Mineralogy, 9: 623651.

Mattos, I.C. 2005. Geologia, petrografia, geoquímica, comportamento físico-mecânico e alterabilidade das rochas ornamentais do stock granítico Serra do Barriga, Sobral, CE. Rio Claro, 260p. Tese de Doutorado,
Programa de Pós Graduação em Geologia Regional, Instituto de Geociências e Ciências Exatas, Universidade Estadual Paulista.

Mattos, I.C., Artur, A.C., Arthaud, M.H. \& Nogueira Neto, J.A. 2007. Geologia e Geocronologia do Stock Granítico Serra do Barriga - Sobral/CE. In: SIMPÓSIO DE GEOLOGIA DO NORDESTE, 23., 2007, Natal. Resumo ... Natal, SBG, v. 1, p. 176.

Navarro, F.C. 1998. Granitos Ornamentais: análise petrográfica na previsão do comportamento físico e mecânico. In: CONGRESSO URUGUAYO DE GEOLOGIA, 2., 1998, Punta del Leste. Anais... Montevideo, SUG, p. $103-107$.

Nogueira, J.F. 2004. Evolução geodinâmica das faixas graníticas de Quixadá Quixeramobim- CE, Rio Claro, 239p. Tese de Doutorado, Programa de Pós Graduação em Geologia Regional, Instituto de Geociências e Ciências Exatas, Universidade Estadual Paulista.

Nogueira Neto, J.A., Fetter, A.H., Santos, T.J.S., Nogueira, J.F. \& Hackspacher, P.C. 1997. Datação U/Pb em Zircão e Idade Modelo (TDM) de Corpo Granítico Sin-Cinemático da Região de Cariré - NW do Ceará. In: SIMPÓSIO BRASILEIRO DE GEOLOGIA DO NORDESTE, 17., 1997, Fortaleza. Boletim de Resumos Expandidos... Fortaleza, SBG Núcleo Nordeste, p. 95-97

Nogueira Neto, J.A Mattos, I.C., Sauerbronn, W.M., Fernandes, A.H.M., Cordeiro, E.R., Nogueira, R.E.F.Q. Cajaty, A.A., Artur, A.C. \&, Sasaki, J.M. 2002. Petrografia e química mineral de dois tipos faciológicos do Granito Serra da Barriga - Sobral (CE): Resultados Preliminares. In: SIMPÓSIO DE ROCHAS ORNAMENTAIS DO NORDESTE, 2., 2002, Recife. Anais... Recife, SBG, p. $49-54$.

Phillips, E.R. 1974. Myrmekite - one hundred years later. Lithos, 7(3): 181-194.

Richard, L.R. 1995. Minpet for Windows-Version 2.02. Minpet Geological Software. Québec.

Robinson, P., Spear, F.S., Schumacher, J.C., Laird, J., Klein, C., Evans, B.W. \& Doolan, B.L. 1981. Phase relations of metamorphic amphiboles: Natural occurence and theory. Reviews in Mineralogy, 9(B): 1-228.

Rodrigues, E.P., Chiodi Filho, C. \& Coutinho, J.J.M. 1997. Importância da petrografia para a previsão do comportamento e da durabilidade de rochas ornamentais. Revista Rochas e Equipamentos, 47: 35-37

Schobbenhaus Filho, C. \& Campos, D.A. 1984. A Evolução da plataforma sul-americana no Brasil e suas principais concentrações minerais. Geologia do Brasil, DNPM, Brasília, p. 9-49.

Streckeisen, A.L. 1976. To each plutonic rock its proper name. Earth Science Review, 12: 1-33. 
